\title{
Enabling health supply chains for improved well-being
}

\section{Lakshmy Subramanian}

\author{
Economic Policy and Performance, Cranfield University, UK
}

lakshmy.subramanian@cranfield.ac.uk

\begin{abstract}
$\underline{\text { Abstract }}$
Health supply chains are necessary for effective health service delivery as they not only provide appropriate health outputs but also have the potentials to create and deliver cost-effective outcomes in line with the economic, social, and cultural conditions of a country. There is a need, therefore, to investigate ways to create functionally appropriate enabling environments that will largely be dependent upon the economic developmental levels in which health supply chains are considered. Under this backdrop, the current study helps in identifying the key enablers for the health supply chains which when present will contribute towards strengthening the health coverage and improving overall well-being. The enabling environment of health supply chains will include the broad structure within which individuals and organizations function. The different enablers are grouped into four broad categories namely (i) people and processes, (ii) systems and data, (iii) investments, and (iv) policies. The study attempts to delineate an integrated model of health supply chain enablers and their role in improving overall well-being. The model is further investigated with Kenya as a case study to understand the impact of the enablers on quality of life and improved well-being.
\end{abstract}

Keywords: Health supply chains; enabling environment; well-being; quality of life 


\section{$\underline{\text { Introduction }}$}

The current scientific knowledge, technological capabilities, and economic resources that we possess have the power to reduce human sufferings caused by poor health and diseases. Yet, unfortunately, an estimated two billion people have no access to essential medicines, effectively shutting them off from the benefits of modern healthcare advancements [54]. It is estimated that one third of the world's population does not have access to medicine [16]. This is undesirable as it can force millions of people into poverty and deepen existing poverty [55]. Although the general understanding is that vulnerable sections of the population often lack the money to purchase essential health commodities, there are empirical evidence to show that health can be improved before income increases [25]. The improved health will boost the economic growth and create more opportunities for income generation.

Motivated by the argument, that health improvements can provide impetus to economic growth, billions of dollars are allocated by different governments and international agencies to improve global health. A recent WHO study reported that health spending now accounts for ten percent of the global GDP [22]. Health spending includes government expenditure, out-ofpocket payments (people paying for their care), and sources such as voluntary health insurance, employer-provided health programmes, and activities by non-governmental organizations. Based on data from data from 2000-2016, health spending is rising almost six percent yearly in low-and-middle-income countries (LMICs), versus four percent in high-income countries, and the low-income countries are lagging in public spending on health. Thus, the essential healthcare commodities still do not reach the last mile at the right quantity, at the right price, at the right time, and in the right place.

It is consequently clear that a key barrier to improved global health is the inadequate capacity of LMICs to procure, manufacture, and distribute essential healthcare commodities. Given this it is imperative to investigate and analyse the dynamics of the various logistic functions which shape the health supply chains [5]. An interconnected network of stakeholders also influences the trajectory of commodities, information, and funds within the supply chain [2]. Therefore, health supply chains are not limited to only warehouses, cartons, and fleet management, but encompasses policies, human resources, information, and technology to maximise the health outcomes in a country.

\section{Significance of health supply chains}

A good health system will necessitate a health supply chain that can deliver and guarantee affordable health commodities at the appropriate quality. Establishing and maintaining wellfunctioning health supply chains that meet the needs of the public and private sectors at all levels, will play a vital role in reducing the unmet needs. Health supply chains act as the firstmile data sources on demand, consumption, and shortages to the health planners [57]. Supply chain management comprises of the steps engaged in moving a commodity from the supplier 
to the customer [21]. Efficient supply chain management improve the quality of care and support care seekers by reducing stock outs of supplies and medical equipment [19]. Supply chain management is a well-developed scientific discipline but has not been fully utilized in improving especially the public health supply chains in developing countries $[26,31]$. This is surprising as close to forty percent of the healthcare expenses are invested in logistics related activities [38].

As a result, health supply chains in LMICs remain sick and ineffective, putting interventions at risk, and weakening the overall health system's ability to deliver quality and equitable healthcare [27]. It is appalling to realize that many of the LMICs where the disease burdens are the highest, health supply chains function poorly, resulting in stockouts and high incidents of fake health commodities. Risks of poor product quality and counterfeiting are further reinforcing the demands to strengthen supply chains [20]. For this reason, there is a growing interest in the global community about whether LMICs will be able to overcome their supply chains bottlenecks and strengthen their existing capacities. It is evident that soon LMICs will have to find a way to procure health commodities themselves in a sustainable way and become less aid dependent [43]. This transition represents both a challenge and an opportunity: a challenge because the developing country governments will have to assume greater responsibility, and an opportunity because the expectation is that this change will force governments to become proactive.

\section{Barriers to health supply chains}

Several factors contribute to weak health supply chains in LMICs especially in the rural and peripherals areas which are heard to reach. The barriers include.

- Weak information systems and inadequate information about logistic management, inventory, financing, and product flow to guide procurement and forecasting [7, 29]

- Inadequate physical infrastructure [42, 44, 54]

- Absence of well-trained and stable human resource dedicated to health supply chain management $[37,30]$

- Inadequate domestic and international funding for procurement of commodities [6, 12]

\section{Purpose of the study}

Health supply chains are the foundation of a well-functioning health system in any country. Like other complex systems, the performance of the health supply chains especially in the LMICs is not fully under the control of those who manage it, having many external influencers (e.g., policy, financing, health system structure). Health supply chain system strengthening should, therefore, be considered as a sub-component of the broader health system strengthening agenda. When designing on supply chain strengthening interventions, one should consider both how the interventions will impact other components, and how those other components will facilitate or constrain supply chain performance. To the best of our knowledge, the literature is still lacking an overall deep understanding of how robust health supply chains can contribute towards increased well-being. Against this background, contributions of this study aim to build from existing work and offer a fresh view in this area. We attempt to sketch an integrated model of health supply chain enablers and their role in improving overall well-being.

\section{Need of the study}


Health supply chains in LMICs differ from commercial supply chains not in the supply chain functions, rather in the factors characterising the environment around them. The enabling environment of health supply chains acts as a key determinant of the effectiveness of health programs and various logistic policies. Therefore, identifying the key components of the enabling environment in the context of health supply chains is substantial for all stakeholders including policymakers, healthcare personnel, logistic professional, international agencies, etc. Without this information, any future recommendations would be made without relevant context.

\section{Methodology}

A search for peer-reviewed sources of relevant information was performed. The search was conducted in PubMed, Science Direct, and Google Scholar. The search also included published information, government documents, and organisation reports of WHO, Ministry of Health (Kenya), UNICEF reports, etc. The search strategy included terms used with and/or includedglobal health, health supply chains, supply chain management techniques, enabling environment, low-and-middle-income countries, health and well-being, Kenya. These key terms and search criteria were used to capture all relevant information. In light of the vast number of sources identified, efforts were made to classify the key enablers of health supply chains into four broad categories namely people and practices, systems and data, investments, and policies.

\section{Outcomes of the research}

Health supply chains are the backbone of the health systems and contribute significantly towards improving health outcomes. Therefore, it is imperative to create an enabling environment for effective health supply chains and aim at improving overall well-being. An enabling environment encompasses sets of policies, institutions, support services and other conditions that collectively improve or create a general business setting where enterprises and business activities can start, develop and thrive [9]. The environment impacts the competitiveness and value creation abilities of the different stakeholders. It will induce enhanced co-operation of stakeholders with different capacities and policies. Therefore, an enabling environment is where systems can thrive and is an essential prerequisite for economic development

Collectively, the world has made remarkable gains in improving health outcomes and following the 2012 Washington call for a renewed commitment, a total of 178 countries have declared their intent to end preventable maternal and child deaths by 2030 (UNICEF Strategic Plan, 2013). However, further progress needs to be made which is all the more strained by the widening inequalities in health and income[51]. Even for those with physical access to health care, poor quality and the associated costs limit the impact of available services leading to further illness and immiseration [18]. Epidemiologic transitions across the developing nations can contribute to the fragility of the health systems thereby necessitating the need to identify drivers to strengthen the health systems in the developing countries [28].

\section{Enablers for robust health supply chains}

The enabling environment of health supply chains will include the broad structure within which individuals and organizations function. Understanding the elements of the enabling environment will require an iterative process of planning, implementing, measuring progress 
and utilizing the new data and information to improve the initial plans, implementation, and measurements. The different components and the associated enablers are categorised into four broad categories
i. People and practices
ii. Systems and data
iii. Investments
iv. Policies

People and practices: All health supply chain activities are driven by people and it is crucial that the attitudes and behaviours of health workers need to be inclusive, non-stigmatizing, and promote safety and equality. According to a WHO study, at least 57 countries have a shortage of health workers, 36 of which are in Africa [46]. The key enablers related to this component are leadership, collaboration, standard operating practices, capacity development, sociocultural and demographic influences, knowledge, education, and awareness,

\begin{tabular}{|c|l|}
\hline Leadership & $\begin{array}{l}\text { Sustainable health supply chain development requires that countries have } \\
\text { committed and empowered leaders who play a vital stewardship role [36]. } \\
\text { When supply chain managers as leaders are empowered and engaged to take } \\
\text { ownership, they can advocate for and ensure the implementation of policies, } \\
\text { guidelines, and strategies that improve health outcomes. }\end{array}$ \\
\hline Collaboration & $\begin{array}{l}\text { This facilitates in identifying the "one truth" to attain integration. } \\
\text { Collaboration can be achieved through public-private partnerships which } \\
\text { will facilitate the mapping of resources and comprehending cultural sources } \\
\text { of truth [11]. }\end{array}$ \\
\hline $\begin{array}{c}\text { Standard } \\
\text { Operating }\end{array}$ & $\begin{array}{l}\text { Standardisation of practices across different partners, regions, and functions } \\
\text { will contribute towards better tracking of medical supplies and improved } \\
\text { health outcomes [49]. This will pave the way for better compliance. }\end{array}$ \\
\hline $\begin{array}{c}\text { Capacity } \\
\text { development }\end{array}$ & $\begin{array}{l}\text { Human resources form the backbone of health supply chains. Hence } \\
\text { identifying their needs, providing opportunities for improvements, and } \\
\text { motivating them through proper incentives will result in improved } \\
\text { performances. }\end{array}$ \\
\hline $\begin{array}{c}\text { Socio- } \\
\text { cultural and } \\
\text { demographic } \\
\text { influences }\end{array}$ & $\begin{array}{l}\text { Cognizance of these factors will help understand the challenges of health } \\
\text { better in any country. Low demand for health interventions often derives } \\
\text { from deep-rooted attitudes that reflect the culture and social norms. } \\
\text { Likewise, gender is an important determinant of health-seeking behavior [4]. }\end{array}$ \\
\hline $\begin{array}{c}\text { Knowledge, } \\
\text { education, } \\
\text { and } \\
\text { awareness }\end{array}$ & $\begin{array}{l}\text { A greater degree of awareness and access to education may enable a person } \\
\text { to recognize early symptoms of illness, resulting in the patient's greater } \\
\text { willingness to seek early treatment [1]. It likewise affects one's efficiency } \\
\text { in maintaining personal health through dietary, hygienic, and preventive } \\
\text { measures. }\end{array}$ \\
\hline
\end{tabular}

Systems and data: A stable supply chain is based on end-to-end visibility of supply and demand data which are used to make informed decisions across the various functions. Most of the supply chains begin with manual reports at the nascent stages and evolve to digital forms to aid in decision making and propel towards supply chain integration. The key enablers in this 
category include technology, data analytics, reporting and feedback, supply chain network and designs.

\begin{tabular}{|c|l|}
\hline Information technology & $\begin{array}{l}\text { A prequisite for seamless information flow is } \\
\text { interoperability between the various stakeholders. The } \\
\text { deployment and operation of information and } \\
\text { communication systems support information sharing [40]. }\end{array}$ \\
\hline Data visibility & $\begin{array}{l}\text { This is the ability of the various components in transit to be } \\
\text { tracked from the manufacturer to the final destination. The } \\
\text { goal is to improve and strengthen logistics by making data } \\
\text { readily available to all stakeholders. }\end{array}$ \\
\hline $\begin{array}{c}\text { Integrated reporting and } \\
\text { feedback }\end{array}$ & $\begin{array}{l}\text { The use of technology in health supply chains will instil a } \\
\text { strong reporting system to ensure that information flows } \\
\text { correctly and consistently [17]. }\end{array}$ \\
\hline designs & $\begin{array}{l}\text { Efficient network design reduces overall supply chain costs, } \\
\text { increase service levels and contribute towards sustainability } \\
\text { [50]. It is essential to understand that supply chains are about } \\
\text { competitive differentiation and sustainable business growth. } \\
\text { This can be achieved by developing networks that suite the } \\
\text { country's requirements and incorporate indigenous resources } \\
\text { [48, 2]. }\end{array}$ \\
\hline
\end{tabular}

Investments: Managing an effective health supply chain is a costly endeavour made more complicated by the numerous stakeholders who might participate in funding parts of the system. Costs could include the cost of acquisition of health commodities, the operating costs of storing and transporting. the capital cost of replenishment and replacement, the advisory cost, etc. The key enablers include funding, infrastructure, and innovations.

\begin{tabular}{|c|l|}
\hline \multirow{5}{*}{ Funding } & $\begin{array}{l}\text { Adequate funding for essential health commodities is essential for ensuring } \\
\text { that people in a country have access to the health services they need and } \\
\text { deserve [53]. Donors have different funding cycles and policies for } \\
\text { committing and disbursing funds, and they are rarely synchronized with each } \\
\text { other or with the country's government budgeting process. Procurement } \\
\text { policies, lead times, and disbursement mechanisms vary significantly. Again, } \\
\text { every supply chain function involves a cost and hence understanding the } \\
\text { overall supply chain cost is very helpful. The results can be used for } \\
\text { supporting advocacy for funding supply chain requirements, providing for } \\
\text { better design, planning, and management of systems. }\end{array}$ \\
\hline Infrastructure & $\begin{array}{l}\text { An integral component of the enabling environment is the investment in all } \\
\text { types of infrastructure including physical, human and technological for } \\
\text { creating robust health supply chains. This will reinforce the strengths of the } \\
\text { supply chain and help the different stakeholders overcome the existing gaps } \\
\text { in performance. }\end{array}$ \\
\hline Innovations & $\begin{array}{l}\text { The potential benefits of innovation in terms of boosting economic growth, } \\
\text { income, and creating jobs are vast. Yet, it is seen that most of the LMICs do } \\
\text { very little to learn from their innovating counterparts [10]. Innovations will } \\
\text { create the required "escalator" wherein the policies and capabilities can be } \\
\text { amalgamated to strengthen the various interventions. }\end{array}$ \\
\hline
\end{tabular}


Policies: An enabling environment establishes the rights and assets of all stakeholders and is governed by a set of policies. These will include plans and guidelines for various legislations, private sector participation, governance, healthcare costs, the maturity of the pharmaceutical sector, quality, and monitoring of the activities. Policies act as catalysis for impact and change to create strong health supply chains.

\begin{tabular}{|c|c|}
\hline Legislations & $\begin{array}{l}\text { This can include the different regulations of a country, political } \\
\text { guidelines, economic policies, taxes, subsidies and sourcing } \\
\text { decisions. Well-defined regulations for pharmaceutical } \\
\text { distribution and strong enforcement will help in the better } \\
\text { structure of the health supply chains in a developing nation. } \\
\text { Legislative constraints can impede a donor from entering the } \\
\text { nation and deprive the health supply chains of external funding } \\
\text { due to low donor confidence. }\end{array}$ \\
\hline Governance & $\begin{array}{l}\text { Policies regarding this will instil a strong sense of accountability } \\
\text { and ownership. This is significant for human resources to take } \\
\text { responsibility for their actions which will translate into an } \\
\text { effective system of improved health outcomes and health } \\
\text { coverage. }\end{array}$ \\
\hline $\begin{array}{l}\text { Private sector } \\
\text { participation }\end{array}$ & $\begin{array}{l}\text { Private sector involvement in the provision of health care can fill } \\
\text { the gaps in public sector participation [Clarke]. This has to be } \\
\text { guided by a collaborative approach which fulfils the demands of } \\
\text { the parties involved }\end{array}$ \\
\hline $\begin{array}{c}\text { Maturity of the } \\
\text { pharmaceutical sector }\end{array}$ & $\begin{array}{l}\text { Strong pharmaceutical companies can aid in better strategies to } \\
\text { fight against disease burdens of a nation as compared to a weaker } \\
\text { industry. The level of centralization and its evolution will } \\
\text { determine whether the pharmaceutical sector in the country is } \\
\text { fragmented or more cohesive in its operations at various levels. }\end{array}$ \\
\hline Healthcare affordability & $\begin{array}{l}\text { This is significantly influenced by the Government's ability to } \\
\text { allocate resources. In most developing countries, the health } \\
\text { system is dominated by very high out-of-pocket expenditures. } \\
\text { Donor funding might be able to increase the volume of health } \\
\text { commodities. However, due to the lack of complete transparency } \\
\text { and communication, this can exert huge pressure on the existing } \\
\text { health supply chain by creating parallel supply chains. }\end{array}$ \\
\hline $\begin{array}{l}\text { Quality inspection and } \\
\text { benchmarking }\end{array}$ & $\begin{array}{l}\text { A major challenge for most of the LMICs is low-quality services, } \\
\text { leaving the effectiveness well short of potential efficacy [15]. } \\
\text { Poor quality of health services can lead to inappropriate } \\
\text { prescribing and treatment too }[3,8,13,52,32] \text {. Adherence to } \\
\text { quality checks and embracing international standardisations helps } \\
\text { in identifying good practices from peers and scaling up the lessons } \\
\text { learned. }\end{array}$ \\
\hline $\begin{array}{l}\text { Monitoring and } \\
\text { evaluation }\end{array}$ & $\begin{array}{l}\text { All components framing the enabling environment will need } \\
\text { constant assessment to understand the relevance and contribution } \\
\text { to creating robust supply chains. This will ensure the different } \\
\text { strategies are in alignment with supply chain objectives and } \\
\text { contribute to the changing needs of the different stakeholders. }\end{array}$ \\
\hline
\end{tabular}




\section{Health supply chains paving the way for enhanced well-being}

Better cognizance of the enabling environment for health supply chains will lead to costeffective supply chains. This will result in affordable healthcare and have a positive impact on overall wellness. Responsible health supply chain management must ultimately be about enhancing long-term wellbeing and not just limited to short-term quick wins. Empirical evidence shows that there is a weak link between wages/salary and well-being because, beyond a certain level, additional income does not make the poorer or richer any more satisfied in the long run [14]. This is because money is only one part of how an individual feel about life, and factors like health, safety, relationships, leisure, etc contribute to the greater well-being.

However, this might be tricky for vulnerable sections of the population who do not have access to basic healthcare commodities. This necessitates the different countries to create an enabling environment whereby the citizenry can be empowered through improved health and the global health supply chains play an integral role in achieving this goal of well-being. Creating an enabling environment for health supply chains also support Governments to strengthen preventive care as they develop more extensive healthcare services. This can encourage greater inter-sectoral coordination, particularly in activities related to prevention and wellness. The study proposes an integrated model of health supply chain enablers (as discussed in the paper) and their role in improving overall well-being (Refer to Figure 1). The model highlights the trajectories of the different activities which will help in establishing and maintaining a higher degree of well-being. The enablers support the evolution of robust and responsible health supply chains that will lead to sustainable, accessible, and affordable healthcare. These important milestones will contribute towards improved quality of life and well-being.

\section{Application of integrated model: An example of Kenya}

Kenya launched its Vision 2030 in 2008 to transform the country at all levels providing a high quality of life to all its citizens. The agenda of the achievement of "Affordable Healthcare for all" has been put on the forefront of Kenya's socio-economic and political agenda. One of the cornerstones to Kenya's health system is the Kenya Medical Supplies Authority (KEMSA) which is a state-owned medical logistics service provider with an important role to avail the required health products and supply chain services i.e. procurement, warehousing, and distribution. It also ensures building the capacity of health workers on forecasting and quantification; to lower the cost of medicines and medical supplies and provide affordable healthcare to the population. In this section, we try to apply the integrated model discussed in this paper to Kenya and investigate how the existing policies have acted as enablers to improve overall well-being.

The objective of this exercise is to learn from Kenya's experience and reiterate the responsibilities of health supply chains to create positive outcomes and greater impacts.

i. People and practices: The Kenya Health Policy supports the country in achieving equitable health by focusing on health using a primary healthcare approach [23]. The KEMSA Act 2013 provided greater autonomy whereby KEMSA could enter into a partnership with NGOs, donors, and private parties. This highlight thought leadership and a strong political commitment to transform the healthcare sector. KEMSA in an attempt to become more professional and transparent in its operations, institutionalised more standard procedures and tools [35]. The country supported the health sector by developing well trained and skilled staff through training and incentives. Staff 
motivation and retention is facilitated through a performance contract and management tool [24]. The Kenyan healthcare landscape is characterised by greater coordination at the national and regional levels through stakeholder forums, county forums and technical working groups [45]. Donors' outsourcing distribution to KEMSA has supported a more collaborative environment within the country. These factors have allowed for devising policies based on the need of the community and improved community engagement and collective leadership.

ii. Systems and data: Utilisation of Enterprise Resource Planning (ERP) and network optimisation techniques have provided more visibility to the Kenyan health system. Technologies such as mobile and internet have high penetration and Kenya has been at the forefront of adoption of mHealth which provides health solutions through mobile phones [33]. Similarly, KEMSA delivers to point of care i.e. the last mile using GPS tracked transportation which is outsourced to third-party logistics service providers [47]. Integration of technology instilled greater adaptability and flexibility in the healthcare pathways.

iii. Investments: Around 1.5 million Kenyan's are pushed into poverty each year as a result of high healthcare costs [33]. Kenya's health financing strategy guides the country in moving towards universal health coverage. The rising out-of-pocket expenditures have continued to burden the population and high user fees also act as major barriers influencing the health-seeking behaviour of the population. Measures are being implemented to take advantage of the period of economic growth and increase investments in health [34]. Large investments in infrastructure development have also been made to improve healthcare delivery.

iv. Policies: The devolution of KEMSA has instilled greater customer-focus and quality in the health system of Kenya. Benchmarking against industry standards and environmental scanning has been adopted as best practices. KEMSA also has a fully developed quality assurance department which ensures that the quality of drugs procured meets international standards [56]. Likewise, in an attempt to design sustainable health supply chains, Kenya has unified the distribution of donor-funded medicines [41]. Also, implementing improvement methodologies and international standards has created a strong culture that promotes excellence [39].

The outcome of the improved health interventions has provided a pathway through which patient safety can be achieved. The key enablers in Kenya have been able to support the improvement of healthcare coverage and address the most important causes of death, ensuring adequate quality of healthcare delivery. Introducing health insurance, increasing the capacity of primary health facilities, supporting the system through well-trained staff and equipment, expansion of maternity wings, etc has resulted in an increase in the Kenyan Essential Package for Health service provided at the health facilities. Efforts to scale up healthcare and logistics initiatives have been important to steer towards greater well-being. A strong relationship especially with people in remote areas who suffer from low accessibility and awareness, was successfully established by focusing on the patient experience, investing in effective marketing channels, and engaging in health education campaigns to promote services. This has led to better recognition of health needs, develop better health strategies, and improve overall wellbeing.

\section{Conclusion}


Strong and robust health supply chains save lives and acts as the backbone of a strong health system. Changing disease patterns and transitions in the economies makes it essential to understand the enabling environment of health supply chains. This is necessary to develop contextual policies and customised guidelines to achieve universal health coverage. Standardised approaches are inadequate for evaluating the health supply chains as the needs can differ across the countries. In formulating policies to strengthen health supply chains, we broadly divided the enablers into four broad categories- people and processes, systems and data, investments, and policies. These key drivers if present will contribute towards creating a strong supply chain for healthcare delivery. While there is wide variation across countries, a 'one size fits all' strategy would be inappropriate. For effective interventions and reforms, a more nuanced appreciation of understanding country-specific factors which will help in creating the required enabling environment for health supply chains. If this approach is embraced, health supply chains can evolve as important contributors to improved quality of life and holistic well-being. 


\section{References}

1. Akin, S., Griffin, Charles C.; David K.; Guilkey and Popkin, Barry M. (1981). The Demand for Child Health Services in the Philippines. Social Science and Medicine 15C (1981), pp: 249-57.

2. Aronsson, H., Abrahamsson, M. and Spens, K. (2011). Developing lean and agile health care supply chains. Supply Chain Management, Vol. 16 No. 3, pp. 176-183. https://doi.org/10.1108/13598541111127164

3. Banerjee A.; Deaton, A, and Duflo, E. (2004). Health care delivery in rural Rajasthan. Econ Polit Weekly 2004; 39:944-9. .

4. Beegle K, Frankenberg E, and Thomas D. (2001). Bargaining power within couples and the use of prenatal and delivery care in Indonesia. Study Family Planning 2001; 32:130-46.

5. Bohmer, R. (2009). Designing Care Harvard Business Press, Boston, MA

6. Chandani, Y. and Breton, G. (2001). Contraceptive security, information flow, and local adaptations: family planning Morocco. African Health Sciences 2001;1(2):73-82.

7. Chandani Y, Andersson S, Heaton A, Noel M, Shieshia M, Mwirotsi A, Krudwig K, Nsona H, Felling B (2014). Making products available among community health workers: Evidence for improving community health supply chains from Ethiopia, Malawi, and Rwanda. J Glob Health. 2014;4(2):020405.

8. Chaudhury, N., Jeffrey, H., Kremer, M., Muralidharan, K. and Rogers, F (2006). Missing in Action: Teacher and Health Worker Absence in Developing Countries. Journal of Economic Perspectives, 20:1, pp. 91-116.

9. Christy, R., Mabaya, E., Wilson, N., Mutambatsere, E. and N. Mhlanga. (2009). Enabling environments for competitive agro-industries. In C. da Silva, D. Baker, A.W. Shepherd, C. Jenane and S. Miranda da Cruz. Agro-industries for development, pp. 136-185. Wallingford, UK, CABI, with FAO and UNIDO. www.fao.org/ docrep/013/i0157e/i0157e00.pdf.

10. Cirera, Xavier, and William F. Maloney. (2017). The Innovation Paradox: DevelopingCountry Capabilities and the Unrealized Promise of Technological Catch-Up. Washington, DC: World Bank. doi:10.1596/978-1-4648-1160-9

11. Clarke L. (2014). Public-private partnerships and responsibility under international law: A global health perspective. Abingdon: Routledge; 2014. p. 5

12. Daff BM, Seck C, Belkhayat H, and Sutton P (2014). Informed push distribution of contraceptives in Senegal reduces stockouts and improves quality of family planning services. Glob Health Scientific Practice 2014;2(2):245-52

13. Dodd R and Munck L. (2001). Dying for change: poor people's experience of health and ill-health. Geneva: World Health Organization/Washington DC: World Bank; 2001.

14. Ed Diener and Robert Biswas-Diener (2002). Will Money Increase Subjective WellBeing?: A Literature Review and Guide to Needed Research. Social Indicators Research Vol. 57, No. 2 
15. Filmer, D., Hammer, J., and Pritchett, L (2000). Weak links in the chain: a diagnosis of health policy in poor countries. World Bank Res Observations 2000; 15:199-224.

16. Foster, S., R. Laing, B. Melgaard, M. Zaffran. (2006). Ensuring supplies of appropriate drugs and vaccines. Disease Control Priorities in Developing Countries, $2^{\text {nd }}$ Edition Oxford University Press, New York, 1323-1338.

17. Gliklich RE, Dreyer NA, and Leavy MB. (2014). Registries for Evaluating Patient Outcomes: A User's Guide, 3rd edition. Rockville (MD): Agency for Healthcare Research and Quality (US); 2014 Apr. 11, Data Collection and Quality Assurance.

18. Haggerty JL, Roberge D, Lévesque JF, Gauthier J, Loignon C. (2014). An exploration of rural-urban differences in healthcare-seeking trajectories: implications for measures of accessibility. Health Place 2014;28:92-8

19. High Impact Practices in Family Planning (HIP). Supply chain management: investing in contraceptive security and strengthening health systems. Washington, DC: USAID; 2012 Nov. Available from: http://www.fphighimpactpractices.org/resources/supplychain-management-investing-contraceptivesecurity-andstrengthening-health-systems (Accessed on January 5, 2020).

20. IOM (Institute of Medicine). 2013. Countering the problem of falsified and substandard drugs. Washington, DC: The National Academies Press.

21. Jacoby, D (2009). Guide to supply chain management: how getting it right boosts corporate performance. John Wiley \& Sons; 2009.

22. $\mathrm{Ke} \mathrm{Xu}$, Agnes Soucat, Joseph Kutzin, Callum Brindley, Nathalie Vande Maele, Hapsatou Toure, Maria Aranguren Garcia, Dongxue Li, Hélène Barroy, Gabriela Flores Saint-Germain, Tomáš Roubal, Chandika Indikadahena, and Veneta Cherilova (2018). Public Spending on Health: A Closer Look at Global Trends. World Health Organization, 2018

23. Kenya Health Policy 2012 - 2030

24. Kenya Health Workforce Report: The Status of Healthcare Professionals in Kenya, 2015

25. Kim, K., and Moody, P.M (1992). More resources better health? A cross-national perspective. Soc. Sci. Med. 34(8): 837-842.

26. Kraiselburd S, Yadav P (2013). Supply chains and global health: An imperative for bringing operations management scholarship into action. Product Operation Management 2013; 22(2): 377-81.

27. Kruk, Margaret E, Gage, Anna D, Arsenault, Catherine. Jordan, Keely et al. (2018). High-quality health systems in the Sustainable Development Goals era: time for a revolution. The Lancet Global Health Commission| Volume 6, Issue 11, Pe1196E1252, November 01, 2018

28. Lagerlof, N.P. (2003). From Malthus to modern growth: can epidemics explain the three regimes?", International Economic Review, Issue: 44, pp: 755-77

29. Lee HL and C Billington. Managing supply chain inventory: pitfalls and opportunities. Sloan Management Review Spring 1992; 33: 65-73.

30. Lebetkin E, Orr T, Dzasi K, Keyes E, Shelus V, Mensah S, Nagai H, Stanback J. (2014). Injectable contraceptive sales at licensed chemical seller shops in Ghana: access and reported use in rural and peri urban communities. International Perspectives on Sex and Reproductive Health. 2014;40(1):21-7

31. McKone-Sweet, K.E., Hamilton, P. and Wills, S.B. (2005). The ailing healthcare supply chain: a prescription for change. Journal of Supply Chain Management, Vol. 41 No. 1, pp. 4-17. 
32. McPake B, Asiimwe D, Mwesiqye F, Ofumbi M, Ortenblad L, Streefland P, et al., (1999). Informal economic activities of public health workers in Uganda: implications for quality and accessibility of care. Social Scientific Medicine 1999; 49:849-65.

33. Ministry of Health. The Kenya household health expenditure and utilisation survey, 2013. Nairobi: Government of Kenya; 2014.Njoroge et al. (2017). Assessing the feasibility of eHealth and mHealth: a systematic review and analysis of initiatives implemented in Kenya. BMC Res Notes (2017) 10:90

34. Njuguna David and Pepela Wanjala (2019). A Case for Increasing Public Investments in Health Raising Public Commitments to Kenya's Health Sector Ministry of Health Policy Brief

35. Nkrumah, Yvonne and Mensah, Julia, eds. 2014. Accelerating Health Reforms through Collective Action: Experiences from East Africa. World Bank Studies. Washington, DC: World Bank. doi:10.1596/978-1-4648-0287-4. License: Creative Commons Attribution CC BY 3.0 IGO

36. Rezaee, Zabihollah (2018), Supply Chain Management and Business Sustainability Synergy: A Theoretical and Integrated Perspective. Sustainability 10, 275, pp: 1-17

37. Prata N, Gessessew A, Cartwright A, and Fraser A. (2011). Provision of injectable contraceptives in Ethiopia through community based reproductive health agents. Bull World Health Organisation 2011;89(8):556-64.

38. Poulin, E. (2003). Benchmarking the hospital logistics process: a potential cure for the ailing health care sector. The Free Library, available at: www.thefreelibrary.com/ (accessed 3 October 2019).

39. Okech, Timothy, and Steve, Lelegwe (2015). Analysis of Universal Health Coverage and Equity on Health Care in Kenya. Global Journal of Health Science 8, no. 7, 2015

40. Ramanathan, Usha \& Gunasekaran, Angappa. (2014). Supply chain collaboration: Impact of success in long-term partnerships. International Journal of Production Economics. 147. 252-259. 10.1016/j.ijpe.2012.06.002.

41. Serem, Daisy (2014). Strategic Partnership to Make the Supply Chain Work for Children and Women in Kenya. UNICEF, 2014,

42. Shieshia M, Noel M, Andersson S, Felling B, Alva S, Agarwal S, and Chandani Y (2014). Strengthening community health supply chain performance through an integrated approach: Using mHealth technology and multilevel teams in Malawi. Journal of Global Health. 2014;4(2):020406.

43. Silverman, Rachel (2017). Projected Health Financing Transitions: Timeline and Magnitude- Working Paper 488. Center for Global Development. July 10, 2018.

44. Sued O, Schreiber C, Giron N, and Ghidinelli M. (2011). HIV drug and supply stockouts in Latin America. Lancet Infect Dis 2011; 11(11): 810-1.

45. Tabitha Kimani et al. (2016). One Health stakeholder and institutional analysis in Kenya. Infection Ecology and Epidemiology 2016, 6: 31191 http://dx.doi.org/10.3402/iee.v6.31191

46. The World Health Report (2006). Global Atlas of the Health Workforce.

47. UNICEF case study titled KEMSA After the Devolution: Financial Sustainability Through A Supply Chain Strategy with A Strong Focus on Human Resources and Leadership

48. USAID Deliver Report (2009). Planning and Implementing A Logistics System Design Activity. March 2009

49. USAID Report (2011). The Logistics Handbook A Practical Guide for the Supply Chain Management of Health Commodities. 2011 
50. Vledder M, Friedman J, Sjöblom M, Brown T, and Yadav P. (2015). Optimal supply chain structure for distributing essential drugs in low income countries: Results from a randomized experiment. Ross School of Business Paper. 2015;1269.

51. Woodward A and Kawachi I (2000).Why reduce health inequalities? Journal of Epidemiology \& Community Health 2000;54:923-929.

52. World Bank (2004). The millennium development goals for health: rising to the challenges. Washington DC: World Bank; 2004.

53. World Bank (2010). From Evidence to Policy, A note series on learning what works, from the Human Development Network, November 2010

54. WHO Report (2017). Ten years in public health 2007-2017

55. Xu, K., D. B. Evans, G. Carrin, A. M. Aguilar-Rivera, P. Musgrove, T. Evans. (2007). Protecting households from catastrophic health expenditures. Health Affairs. 6: 972983.

56. Yadav, Prashant (2014). Kenya Medical Supplies Authority (KEMSA) A case study of the ongoing transition from an ungainly bureaucracy to a competitive and customer focused medical logistics organization. World Bank study

57. Yadav, Prashant (2015). Health Product Supply Chains in Developing Countries: Diagnosis of the Root Causes of Underperformance and an Agenda for Reform, Health Systems \& Reform, 1:2, 142-154, DOI: 10.4161/23288604.2014.968005 